\title{
INCONSISTENCIAS: LA SENTENCIA DEL TRIBUNAL CONSTITUCIONAL ALEMÁN DE 18 DE JULIO DE 2005 SOBRE LA ORDEN EUROPEA DE DETENCIÓN Y ENTREGA*
}

\author{
CHRISTIAN TOMUSCHAT \\ Catedrático emérito de Derecho público, internacional y europeo \\ Universidad Humboldt de Berlin
}

SUMARIO

I. Introducción.

II. La naturaleza jurídica de la segunda frase del art. 16.2 de la Ley Fundamental.

III. Las críticas al contenido de la Ley sobre la orden europea de detención.

IV. Vicios de la Ley alemana sobre la orden europea de detención referidos al procedimiento de tutela judicial.

$\mathrm{V}$. Observaciones finales.

\section{INTRODUCCIÓN}

Mucho y bueno hubiera cabido esperar de la sentencia del Tribunal Constitucional alemán de 18 de Julio de 2005 sobre la orden europea de detención ${ }^{1}$.

* Ungereimtes/Zum Urteil des Bundesverfassungsgerichts vom 18. Juli 2005 über den Europäischen Haftbefehl, publicado en Europäische Grundrechte Zeitschrift 2005, pp. 453 y ss. Traducción de Ignacio GuTiÉrRez GuTiÉrREz.

1 EuGRZ 2005, pp. 387 y ss. [N. del T.: El autor del artículo precisa en notas ulteriores las páginas de esta revista en las que cabe encontrar los pasajes concretos a los que se refieren sus citas y comentarios; nos hemos permitido en esta traducción ir sustituyendo tal dato por la indicación de los párrafos correspondientes, numerados en la propia sentencia (Abs.). Entretanto, la resolución puede ser ya citada del modo convencional (BVerfGE 113, 273), una vez publicada en la colección editada por el propio Tribunal. El texto se encuentra asimismo en la dirección de internet http://www.bverfg.de/entscheidungen/rs20050718_2bvr223604.html]. 
Pero la resolución de Karlsruhe resulta más bien decepcionante. Tampoco abre nuevas perspectivas de futuro para configurar la integración europea; de la que, como hasta ahora, sólo sabemos que avanza mucho más allá del status de una organización internacional "clásica", sin haber llegado a alcanzar el nivel de la estatalidad, por lo que ha de sobrevivir con la indeterminada denominación de "liga de Estados" (Staatenverbund) ${ }^{2}$. Una y otra vez, de modo casi inevitable, surgen tensiones, porque la Unión Europea y la Comunidad Europea asumen de forma creciente funciones que no sólo afectan a aspectos secundarios de las tareas públicas, sino que están íntimamente integradas en los pilares esenciales de la estatalidad de los Estados miembros. Evidentemente, el Derecho penal pertenece a ese núcleo. Con razón ha dedicado por ello el Tribunal Constitucional alemán una atención especial al primer caso en que ha tenido que enfrentarse a la orden europea de detención.

La relevante singularidad de la orden europea de detención, que para todos los Estados miembros de la Unión Europea tiene como base jurídica la Decisión Marco del Consejo de 13 de junio de 2002 "sobre la Orden europea de detención y los procedimientos de entrega entre los Estados miembros" (en adelante "la Decisión Marco" $)^{3}$, se funda en el hecho de que un acto soberano de otro país, una orden de arresto, ha de ser ejecutado "sobre la base del principio del reconocimiento mutuo" (art. 1.2 de la Decisión Marco). Pero no se trata ciertamente de un trámite que se cumplimente de forma mecánica ${ }^{4}$. Bajo determinadas circunstancias, que son precisadas por los arts. 3 y 4 de la Decisión Marco, un Estado puede o debe negarse a tal ejecución. Por ello, también conforme a la nueva regulación se exige un procedimiento formal en el Estado que recibe tal orden de detención, mediante el cual se decide sobre la "entrega" de la persona buscada. En cualquier caso, la orden europea de detención sigue siendo un instrumento jurídico que presupone una considerable confianza en las relaciones recíprocas de los Estados miembros de la Unión. El proceso se acelera precisamente porque, a solicitud de un Estado, una persona determinada debe ser aprehendida y entregada, sin que sea necesario que el Estado requerido produzca antes una orden nacional de detención conforme a sus propias reglas.

2 BVerfGE 89, 155 (184, 190).

3 Decisión Marco 2002/584/JAI, Diario Oficial de las Comunidades Europeas L 190/1, 18.7.2002. Sobre sus precedentes véase esp. BT-Drucksache 15/1718, 15.10.2003, p. 9; también Nicola VENNEMANN, "The European Arrest Warrant and its Human Rigths Implications", ZaöRV 63 (2003), pp. 102 y ss., esp. 104-108; y Jürgen JEKEWITZ, "The Aktion of the European Union to Combat Terrorism", en Societé française pour le Droit International (ed.), Les nouvelles ménaces contre la paix et la sécurité internationales, Paris 2004, pp. 77 y ss., esp. 77-82.

4 Conforme al $₫ 78$ de la Ley de asistencia jurídica internacional en materia penal, es en principio aplicable el procedimiento general de extradición en cuanto la Ley sobre la orden europea de detención no haya introducido reglas particulares. Por lo tanto, debe producirse una decisión judicial en Alemania en especial sobre la admisibilidad de la detención orientada a la extradición, en concordancia con el art. 104.2 de la Ley Fundamental (\$\$ 15 y 16 de la Ley de asistencia jurídica internacional en materia penal). El concepto de "sistema de libre circulación de decisiones judiciales en materia penal", tal y como es utilizado en el punto 5. del preámbulo de la Decisión Marco, es un disparate burocrático. 
Entre los rasgos esenciales de la orden europea de detención se incluye el que también puede estar referida a nacionales del Estado requerido, y prevé su entrega; así como que, respecto de treinta y dos grupos de delitos, se renuncia a la exigencia de doble tipificación penal propia del derecho de extradición; en este último caso, el delito debe estar castigado en el Estado requirente con una pena (o medida de seguridad) máxima privativa de libertad de al menos tres años de duración (art. 2.2 de la Decisión Marco) 5 . Se excluye asimismo la discrecionalidad política del Estado requerido. También se abandona definitivamente la excepción tradicional del "delito político". Ahora bien, cuanto se gana en eficiencia no permite recortar la tutela jurídica. La aceleración debe servir para evitar dificultades burocráticas innecesarias, pero sin que se pierdan las garantías del Estado de Derecho, por más que uno de los objetivos de la orden europea de detención sea intensificar la lucha contra el terrorismo.

Conforme al art. 34.2 b) TUE, la Decisión Marco, como acto jurídico, carece de eficacia directa; aunque, como las directivas del art. 249.3 TCE, vincula a los Estados miembros a lograr el fin perseguido por la norma. Por ello era precisa su incorporación al Derecho alemán. Eso hizo la Ley sobre la orden europea de detención $(\mathrm{EuHbG})^{6}$, que contenía preceptos que reformaban la Ley sobre asistencia jurídica internacional en materia penal (IRG). El procedimiento que se tramitaba contra el recurrente en amparo se fundaba en tales preceptos integrados desde hace aproximadamente un año en la Ley sobre asistencia jurídica internacional en materia penal.

Como es sabido, la extradición de un alemán a otro Estado estaba originariamente prohibida por la Ley Fundamental (frase primera del art. 16.2 GG). Sólo la cuadragésimo séptima ley de reforma de la Ley Fundamental ${ }^{7}$ suavizó en el año 2000 tan rígida prohibición. Según la nueva frase incorporada al art. 16.2 de la Ley Fundamental,

Mediante ley puede establecerse una regulación que permita la extradición de un alemán a un Estado miembro de la Unión Europea o a un tribunal internacional, siempre que se garanticen los principios del Estado de Derecho.

Se evitó, pues, permitir la extradición de un alemán a cualquier tercer Estado. La reforma constitucional eludió especialmente reconocer como base suficiente de legitimación que el Estado requirente hubiera suscrito la Convención Europea de Derechos Humanos o incluso el Pacto Internacional de Derechos Civiles y Políticos. De hecho, hay motivo para estar seriamente pre-

5 La Decisión Marco prefiere los términos "Estado miembro emisor" y "Estado de ejecución".

6 De 21.7.2004, BGBl I, pp. 1748 y ss. Sobre ella Heiko AHLBRECHT, «Freier Personenverkehr innerhalb der Europäischen Union in Auslieferungssachen - die Umsetzung des Europäischen Haftbefehls in das deutsche Rechtshilferecht, Strafverteidiger 2005, pp. 40-47; Lyane SAUTNER, "Die Vollstreckung eines Europäischen Haftbefehl nach dem EU-JZG", Österreichische Juristen Zeitung 2005, pp. 328-343; Helmut SEITZ, "Das Europäische HaftbefehlsgesetZ", NStZ 2004, pp. 546-549.

7 De 29.11.2000, BGBl I, p. 1633. 
ocupados justamente con respecto a los asuntos de justicia en no pocos de los cuarenta y cinco Estados que son hoy parte de la Convención ${ }^{8}$. La Ley alemana sobre la orden europea de detención se acogió a la nueva reserva de ley; por ello, debía establecer los presupuestos para la entrega también de ciudadanos alemanes a otros Estados miembros de la Unión Europea, que bien pueden ser considerados como especialmente dignos de confianza. La norma estructural del art. 6 TUE es el punto de apoyo al respecto. A juicio del Tribunal Constitucional alemán, el intento de regulación fue deficiente, porque el legislador no tuvo suficientemente en cuenta sobre todo el principio de proporcionalidad.

\section{LA NATURALEZA JURÍDICA DE LA SEGUNDA FRASE DEL ART. 16.2 DE LA LEY FUNDAMENTAL}

Como punto de partida para su análisis, el Tribunal adopta una perspectiva conforme a la cual la estrecha cooperación de los Estados miembros de la Unión de acuerdo con el Título VI TUE a fin de lograr una extradición rápida resulta valorada, en lo esencial, como un sacrificio para la sustancia que conforman los principios del Estado de Derecho. La lógica del procedimiento de un recurso de amparo tienta a partir de tal prejuicio, pero no lo impone; menos aún cuando se aprecia que el Tribunal ha estructurado sus explicaciones conforme al modelo del control abstracto de normas, sin ocuparse en detalle del caso concreto o de las implicaciones para el recurrente. En ningún lugar se examina la especial afectación a los derechos fundamentales del recurrente; la supuesta lesión es deducida simplemente del hecho de que la Ley sobre asistencia jurídica internacional en materia penal, en la redacción que le da la Ley sobre la orden europea de detención, no satisface las exigencias generales en materia de derechos fundamentales que derivan de los arts. 16.2, frase segunda, y 19.4 GG, y por ello también de los arts. 2.1 y 20.3 GG.

En la perspectiva general del Tribunal aparece en primer plano la decisión de la primera frase del art. 16.2 GG, la libertad de los ciudadanos alemanes frente a la extradición a un tercer Estado (que no debería ser denominada $l i$ bertad de extradición), mientras que la extradición permitida hacia un Estado miembro de la Unión Europea o hacia un tribunal internacional, conforme a la frase segunda del art. 16.2 GG, resulta exclusivamente considerada como una excepción: "De todos modos, conforme a la frase segunda de este precepto, esta protección puede ser limitada para determinados supuestos mediante Ley" ${ }^{9}$. En este pasaje, que determina la dirección que ha de tomar la argumentación ulterior, el Tribunal no sabe qué más decir. Se harán luego extensas consideraciones sobre las valoraciones que subyacen a la prohibición de ex-

8 El balance no resulta satisfactorio ni siquiera con referencia a los "antiguos" Estados miembros de la Convención. Francia hubo de asumir en el año 2004 no menos de 59 condenas, Italia 36. La mayor parte de estas condenas se referían a defectos en el procedimiento judicial.

9 Sección B.I.1 de la sentencia, Abs. Nr. 63. 
tradición y sobre los antecedentes históricos ${ }^{10}$ (aunque ciertamente no aparezcan aquí puntos de vista decisivos, en concreto la arbitrariedad judicial frente a los prisioneros de guerra alemanes por parte en especial de la Unión Soviética ${ }^{11}$ ). También en las reflexiones que siguen sobre el contenido y alcance de la frase

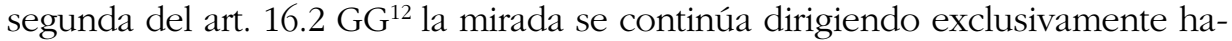
cia el aspecto negativo: el precepto es considerado — con toda razón desde el punto de vista técnico-jurídico- como apertura de un "permiso de intervención" en el derecho fundamental a no ser extraditado, anteriormente garantizado sin reserva. Significativamente, el Tribunal se plantea si quizá la reforma constitucional del año 2000 no habría podido ser inconstitucional por atentar contra el art. $79.3 \mathrm{GG}^{13}$. El Tribunal rechaza tal hipótesis con unas pocas frases; pero llama la atención que, a continuación, el Tribunal, en un apartado (relativamente enjuto) que habría de mostrar cómo se incardina la orden europea de detención en el proceso de integración europea, se limite en lo sustancial a observar que, en el marco de la construcción de un "espacio de libertad, seguridad y justicia", los Estados miembros han renunciado, mediante una más estrecha cooperación en materia penal, a la discrecionalidad política que por lo demás les corresponde en materia de extradición. Cuando, para aclararlo, se dice que esa cooperación debería apoyar el proceso "de desarrollo conjunto y la apertura de las fronteras para personas, mercancías, servicios y capital", queda bastante claro que el Tribunal no hace justicia al impulso político dado hace ya más de diez años por el Tratado de Mastrique, y que se ha queda estancado en la lógica superada del Tratado de la Comunidad Económica Europea. A tal forma de ver las cosas se ajusta el hecho de que el Tribunal plantee en este momento, una vez más, si no se estará atentando contra el art. 79.3 GG mediante una "desestatalización" que vaya demasiado lejos ${ }^{14}$. El art. 23.1 GG solamente es mencionado como límite de la integración, en la medida en que el Tribunal remite al principio de subsidiariedad recogido en el mismo, principio que por lo demás inspira el núcleo de la crítica contenida en el voto particular del Magistrado Bro $\beta^{15}$.

Una interpretación objetiva, que se hubiera atenido a las decisiones contenidas en la Constitución sobre el futuro desarrollo de la comunidad política, debería haber colocado los acentos de modo diferente. En el art. 23.1 GG se dice expresamente que la República Federal de Alemania colabora en el desarrollo de la Unión Europea. En 1992/93, cuando se creó la Unión Europea como marco político para las tres Comunidades, la finalidad declarada de todos los Estados miembros era ampliar la vinculación existente hasta ese momento más allá de la dimensión exclusivamente económica. La introducción de la

10 Sección B.I.1 a), Abs. Nr. 64-68. Cfr. al respecto la crítica de la Magistrada Lübbe-Wolff en su voto particular, sección 1.a), Abs. Nr. 156-157.

11 Véanse al respecto las alusiones realizadas durante las sesiones del Consejo Parlamentario que redacta la Ley Fundamental por parte del Dr. Seebohm, JöR N.F. 1 (1951), p. 169.

12 Sección B.I.1.b), Abs. Nr. 69 y ss.

13 Sección B.I.1.b) aa), Abs. Nr. 70.

14 Sección B.I.1.b) cc), Abs. Nr. 74-75.

15 Abs. Nr. 132-153. 
ciudadanía europea, con los derechos políticos asociados a ella, da claro testimonio de tales propósitos. Pero también la "Cooperación en los ámbitos de Justicia e Interior" entonces acordada (Título VI del Tratado de la Unión en su versión de Mastrique) era una parte integrante del proyecto político que en ese momento se ampliaba de modo cualitativo. Esta conexión no aparece en parte alguna de los fundamentos jurídicos de la sentencia. El art. 23.1 GG está en estrecha relación con la frase segunda del art. 16.2 GG, y por ello debería haber sido incorporado a la argumentación. Pero también este último precepto, justamente por no estar viciado de inconstitucionalidad y constituir así un elemento completamente válido de la estructura constitucional, imponía que se atendiera a su pronunciamiento positivo sobre la cooperación europea como decisión constitucional determinante. En lugar de esto, a las dos frases del art. 16.2 GG se les atribuye un peso desigual. La segunda aparece más bien como una anomalía, como una mera limitación, mientras que la sustancia axiológica del 16.2 GG quedaría incorporada exclusivamente en la frase primera. Pero lo cierto es que la reserva de ley especial de la frase segunda del art. 16.2 GG se distingue significativamente de la mayoría de las reservas de ley, que mediante expresiones generales simplemente permiten restricciones de los correspondientes derechos fundamentales, en la medida en que aparece como instrumento para realizar los fines proclamados en el art. 23.1 GG. De ese modo, el enjuiciamiento del Tribunal Constitucional queda desde un principio encauzado en un curso marcado de forma preliminar y dominante por la estatalidad de la República Federal y por su especial sistema de protección jurídica, en lugar de reflejar la apertura experimentada por el sistema constitucional alemán en el año 1993 a través del art. 23.1 GG.

Naturalmente, no se trata de dar aquí la palabra a una ingenua "euforia europeísta". No todo lo que lleve la etiqueta de europeo es bueno sólo por ello ${ }^{16}$. Pero es muy diferente que un derecho fundamental se limite en atención a cualesquiera fines que puedan resultar de la política cotidiana, o que se persigan objetivos estructurales a largo plazo a los que el propio legislador constituyente ha dado su conformidad, al incorporarlos en forma de principios mediante reforma constitucional. En esa medida ha de achacarse a la sentencia una laguna argumental que deja insatisfecho al lector.

\section{LAS CRÍTICAS AL CONTENIDO DE LA LEY SOBRE LA ORDEN EUROPEA DE DETENCIÓN.}

\section{III.1. El DEBER DE ATENDER A LAS CIRCUNSTANCIAS DE HECHO}

La autorización para conceder la extradición de un ciudadano alemán a una autoridad extranjera dotada de potestad penal comporta también, sin ninguna duda, una intervención en un derecho fundamental. El legislador consti-

16 En algún extremo excesiva parece sin embargo la crítica de Bernd SCHÜNEMANN, "Europäische Haftbefehl und EU-Verfassungsentwurf auf schiefer Ebene", ZRP 2003, pp. 185-189. 
tucional subraya con igual claridad su preocupación por los derechos de los afectados mediante el añadido de que la extradición podrá tener lugar "siempre que se garanticen los principios del Estado de Derecho", y sólo en tal caso. Conforme a las reglas generales elaboradas a lo largo de décadas de reflexión por la jurisprudencia del Tribunal en materia de derechos fundamentales ${ }^{17}$, debe garantizarse en ese ámbito el respeto al principio de proporcionalidad. En esa medida cabe asumir plenamente la argumentación ulterior. Por más que el Tribunal deslice una formulación al menos equívoca, cuando afirma que el legislador mismo deberá verificar "si dichos presupuestos propios del postulado del Estado de Derecho resultan satisfechos por las instancias requirentes ${ }^{18}$. Como ha señalado con razón la Magistrada Lübbe-Wolff en su voto particular, tal comprobación de los casos particulares no puede ser tarea que se asigne al legislador mismo, y no sólo por razones fácticas, sino también jurídico-constitucionales $^{19}$. Quizá no se deba suponer que el Tribunal, mediante tal expresión, haya querido señalar que debiera establecerse un sistema equivalente al previsto en el art. 16 a, apartados 2 y 3 de la Ley Fundamental, que conlleva dificultades interminables. De todos modos, resulta correcto asumir que la confianza ciega en la garantía del Estado de Derecho por parte de los demás miembros de la Unión Europea no puede ser la solución adecuada. Si se llegara a constatar en otro Estado de la Unión un deterioro general de las garantías procesales esenciales, entraría en juego en todo caso el $₫ 73$ de la Ley sobre asistencia jurídica internacional en materia penal ${ }^{20}$, conforme al cual no cabe prestar la asistencia jurídica cuando ésta "contradiga principios esenciales del ordenamiento jurídico alemán". Este precepto concuerda con la jurisprudencia del Tribunal, para la cual impiden en todo caso una extradición los principios constitucionales irrenunciables que fueran puestos en peligro por ella con perjuicio para el afecta$\mathrm{do}^{21}$, y también, por lo demás, con el art. 6 TUE, la norma que orienta todo el Derecho de la Unión. Además, y en ello hay que dar la razón al Tribunal, en tal situación estaría obligado el legislador a establecer normativamente medidas generales de protección, incluso con independencia de un eventual procedimiento conforme al art. 7 TUE $^{22}$.

El recurrente había planteado dos objeciones de principio frente a los correspondientes preceptos de la Ley sobre asistencia jurídica internacional en materia penal en la redacción que les da la Ley sobre la orden europea de detención. Por un lado, como ya ocurrió en el proceso sobre el Tratado de Mastrique, se alega la lesión del principio democrático, dado que la intervención del Parlamento Europeo en la adopción de la Decisión Marco se ha limitado a

17 Cfr. por ejemplo, en los últimos tiempos, BVerfGE 110, 1 (28 y ss.); 141 (163 y ss.); 177 (193 y ss.); 226 (262 y ss.); BVerfGE 109, 96 (111 y ss.).

18 Sección B.I.1.c) aa), Abs. Nr. 77.

19 Sección 4, Abs. Nr. 174-175.

20 Cfr. también $₫ 49$ (1), Nr. 2, de la Ley sobre asistencia jurídica internacional en materia penal.

21 BVerfGE 75, 1 (19).

22 Sección B.I.1.c) aa), Abs. Nr. 77-79. 
la consulta previa, de conformidad con el art. 39 TUE. Por otra parte, el recurrente argumenta que la orden europea de detención es una medida que va más allá del marco fijado por el art. 23.1 GG y que conduce claramente a la desestatalización de la República Federal. El Tribunal rechaza ambos argumentos.

\section{III.2. Déficit DEMOCRÁtico}

El Tribunal despacha el reproche de quiebra del principio democrático con relativa brevedad, indicando que, en el ámbito del "tercer pilar", los órganos legislativos de los Estados miembros conservan eel poder de configuración política en el marco de la transposición, y en caso necesario también negándose a tal transposición ${ }^{23}$. En verdad que la objeción podría haberse abordado de forma más acertada. Si se toman como punto de partida los principios del Derecho internacional, que bien pueden considerarse reclamados en el "tercer pilar", resulta completamente inusual que un acuerdo llegue a resultar vinculante antes de haber sido aceptado por las cámaras parlamentarias. Conforme al modelo que ha encontrado acogida en el art. 59.2 GG y que se corresponde con la práctica constitucional hoy generalizada cuando menos en Europa, los compromisos internacionales de cierta importancia precisan del acuerdo parlamentario antes de que el órgano nacional capacitado para la representación exterior pueda dar cumplimiento al trámite de la ratificación. Sin duda alguna, una decisión sobre un trámite simplificado de extradición concierne a una cuestión de tal importancia, puesto que es un derecho fundamental - la protección frente a la extradición - el que padece en este caso una injerencia. Con el régimen introducido por la orden europea de arresto, el ciudadano se ve sometido a la potestad penal de un Estado extranjero, y ello en los treinta y dos grupos de delitos en los que no rige la tradicional garantía de que haya de tratarse de un hecho también tipificado penalmente en el propio país.

Los parlamentos de todos los Estados miembros vieron predeterminada su acción mediante la adopción de la Decisión Marco, al menos en lo que concierne a los elementos esenciales de la orden europea de detención, dado que lo único que les resultaba permitido era fijar las modalidades específicas de ejecución en concordancia con la sistemática de cada ordenamiento nacional. Remitirse aquí a la posibilidad de denunciar en caso necesario el obligado acatamiento de las normas de la Unión no ofrece respuesta válida para el problema planteado, como acertadamente señala de nuevo la Magistrada LübbeWolff ${ }^{24}$. En las actuales circunstancias cabe sin embargo argumentar sin particulares dificultades que el legislador nacional ha prestado su acuerdo de forma anticipada. Porque la tarea propuesta por el Tratado de la Unión Europea en relación con estas cuestiones no ha sido atribuida en términos generales, aunque

23 Sección B.I.1.c) bb), Abs. Nr. 81.

24 Sección 5. Abs. Nr. 176-180. 
tampoco quede especificada. Más bien, el programa de acción que los firmantes del Tratado perfilaron en el art. 31.1 b) TUE se corresponde exactamente con las exigencias definidas por el Tribunal Constitucional en la sentencia sobre el Tratado de Mastrique ${ }^{25}$. Cuando allí se dice que los Estados miembros, en el marco de la acción en común sobre cooperación judicial en materia penal, están de acuerdo también en facilitar "la extradición entre los Estados miembros", estamos ante una descripción que bien podría equivaler a las precisiones exigidas por el art. 80.1 GG para conceder las habilitaciones que permiten dictar reglamentos jurídicos. Si el art. 31.1 b) TUE estuviera contenido en el Tratado de la Comunidad Europea, nadie podría dudar seriamente de su conformidad con el denominado "principio de atribución", que exige que las habilitaciones a la Comunidad sean específicas y limitadas. Mientras se vea el acto de legitimación democrática decisivo en la aprobación de los tratados por los parlamentos nacionales, y por lo demás se acepte un ejercicio del poder público por parte de órganos integrados por personas cuya legitimación democrática es sólo indirecta, poco puede importar que se realice una auténtica transferencia de competencias soberanas, en cuyo ejercicio las instancias nacionales ya no tendrán papel alguno que jugar, o que se atribuya una competencia ejercitable en régimen de cooperación intergubernamental, en la que ciertamente los órganos legislativos nacionales aún conservan una función de transposición y ejecución, aunque modesta. Bien al contrario, la interferencia en la sustancia democrática pesará menos en este segundo caso.

Por lo demás, justamente en el ámbito propio del Derecho internacional no debería otorgarse importancia desproporcionada a la función decisoria que en Alemania corresponde al Bundestag y al Bundesrat en materia de tratados internacionales. Bien cierto es que, antes de adoptar el acto vinculante desde el punto de vista internacional, los tratados requieren la conformidad parlamentaria en los términos establecidos por el art. 59.2 GG. Pero aún así es necesario constatar que, si se atiende a la realidad de los hechos, y teniendo en cuenta la complejidad de los procesos de negociación y acuerdo en el ámbito internacional, cuando finalmente los textos se ponen sobre la mesa "la suerte está echada". Al Parlamento le corresponde "en realidad ya sólo una consideración $a$ posteriori ${ }^{26}$. Lo importante es, pues, que en cada caso los órganos dotados de legitimación democrática directa se incorporen a tiempo al proceso de negociación y pongan en valor sus concepciones. Solo entonces estarán en situación de contribuir con éxito a la configuración de los proyectos normativos. Ello presupone naturalmente una información precisa y, sobre todo, adecuada a la importancia y significado de los diversos proyectos, que parece asegurada al menos conforme al tenor de la Ley sobre la colaboración del Gobierno Federal y el Bundesrat en asuntos referidos a la Unión Europea ${ }^{27}$ y de la Ley sobre la cola-

25 BVerfGE 89, 155 (187 s.).

26 Christian TOMUSCHAT, "Der Verfassungsstaat im Geflecht der internationalen Beziehungen", en VVDStRL 36 (1978), pp. 7 y ss. (p. 31 para la cita).

27 De 12 de marzo de 1993, BGBl. I, p. 311. 
boración de la Federación y los Länder en asuntos referidos a la Unión Euro$p a^{28}$. Las Cámaras parlamentarias, a través de las vías de información institucionalizadas por estas leyes, pueden asegurar su influencia, con independencia de que se trate de medidas previstas en el ámbito del Derecho de la Comunidad o de medidas del "tercer pilar".

Sin embargo, es evidente que los Parlamentos fallaron en los - entonces- quince Estados miembros. Solo así cabe explicarse que hayan sido incorporados a la Decisión Marco sobre la orden europea de detención tipos penales tan vagos y poco perfilados (tomando como referencia las exigencias del Estado de Derecho) como el delito informático, el racismo y la xenofobia y el sabotaje $^{29}$. Por lo que se sabe, ninguno de los miles de parlamentarios que existen en Europa (todos ellos recibieron información de uno u otro modo) ha protestado contra este "gabinete de los horrores" y exigido a su Gobierno que rechazara el acuerdo. Pero también fallaron los Ministros de Justicia, que han dejado plena libertad a sus funcionarios sin cobrar conciencia de la delicada naturaleza de estos tipos penales, susceptibles de las más diferentes interpretaciones y que difícilmente cabe reducir al terreno común de los valores europeos. Es evidente que en la masa de los asuntos europeos falta el hilo conductor que identifica las cuestiones fundamentales, en las que realmente puede hablarse de una amenaza para la libertad de los ciudadanos.

Con tales reflexiones, que apuntan a la definición precisa del programa normativo establecido en el art. 31.1 b) TUE, ciertamente no queda solventado con carácter general el problema de la legitimación democrática. Sin embargo, ya la sentencia del Tribunal Constitucional alemán sobre el Tratado de Mastrique llegó a la conclusión de que, al menos provisionalmente, mientras continuara existiendo la actual liga de Estados (Staatenverbund), el compromiso debe servir como parámetro general ${ }^{30}$. De un lado, se lamenta un déficit democrático; pero cada vez que se amplian y profundizan significativamente las competencias del Parlamento Europeo aparece indefectiblemente el reproche de la desestatalización, que también el Tribunal se toma muy en serio y admite como argumento legítimo. Habrá que acostumbrarse a convivir durante algún tiempo con ciertas provisionalidades, que se corresponden perfectamente con la situación en la que se encuentra el proceso de integración europea — «ólo

28 De 12 de marzo de 1993, BGBl. I, p. 313.

29 Con acuerdo generalizado critica la doctrina ante todo estos tres grupos de delitos; cfr. AHLBRECHT, cit. en n. 6, p. 41, que habla incluso de un "escarnio" a "la política criminal liberal de la Europa continental que se ha ido consolidando gracias a un desarrollo secular,; Ewa M. GUZIK MAKARUK, "Ne bis in idem, Europäischer Haftbefehl und der Verfassungsentwurf für Europa aus polnischer Sicht", ZStW 116 (2004), pp. 372 y ss. (p. 374); Gustavo PANSINI, "La réception du mandat d'arrêt européen en Italie,, en Marie-Elisabeth CARTIER (ed.), Le mandat d'arrêt européen, Bruselas 2005, pp. 179 y ss. (p. 181); SCHÜNEMANN, cit. en n. 16, p. 188. También críticos por falta de precisión jurídica en el listado del art. 2.2 de la Decisión Marco Michel MASSÉ, "La décisioncadre", pp. 47 y ss. (p. 59) y Cristina MAURO, "Réflexions à propos de la loi introduisant le mandat d'arrêt européen en France", pp. 201 y ss. (p. 210: "categorías bastante imprecisas"), ambos en Le mandat d'arrêt européen, cit.

30 BVerfGE 89, 155 (186 s.). 
lo provisional permanece". La soberanía nacional y el poder de la Comunidad y de la Unión deben ser conducidos a un difícil equilibrio. Es preciso reconocer que, por su propia naturaleza, este sistema de varios niveles no puede mostrar la coherencia, la elegancia, la precisión y el impulso de los sistemas constitucionales nacionales. El peligro real no consiste tanto en una negación del poder democrático de decisión a costa del demos, como en la imposibilidad de aprehender el propio sistema en su conjunto, lo que a la postre conduce a difuminar cualesquiera responsabilidades. Además, es evidente desde muchos puntos de vista que los parlamentos nacionales hasta ahora no han cobrado conciencia en absoluto de las posibilidades abiertas a su capacidad de influencia, y de la responsabilidad que también con ello se les atribuye, a la hora de configurar los procesos políticos en Europa mediante los diversos mecanismos que, al margen de los procedimientos más rutinarios, les permiten incidir sobre sus gobiernos ${ }^{31}$.

\section{III.3. "DESESTATALIZACIÓN"}

El Tribunal dedica una atención extraordinaria al reproche de la "desestatalización ${ }^{32}$. Como ya se ha subrayado, este reproche no resultó finalmente acogido por la decisión de los magistrados, por más que fuera aceptado como topos argumental. En el correspondiente apartado, el Tribunal establece límites sólidos, en concordancia sustancial con la Sentencia sobre el Tratado de Mastrique $^{33}$. El Estado debería retener tareas "de importancia sustancial", "tareas esenciales del Estado" no podrían ser objeto de renuncia. Menos fácil de ver es la razón por la que en este contexto se rechaza, de forma un tanto admonitoria, una "armonización general del Derecho penal de los Estados miembros". ¿Por qué una liga de Estados (Staatenverbund), que se ve a sí misma como una comunidad política con valores comunes, no puede proponerse una armonización del Derecho penal, que ha de ser concebido justamente como instrumento para proteger tales valores comunes ${ }^{34}$ ? Por lo demás, si se observa el catálogo de tipos penales contenido en el art. 2.2 de la Decisión Marco, se constata que evidentemente hay infracciones jurídicas acerca de cuya penalización existe plena unanimidad. Desde la perspectiva del Derecho constitucional alemán, no parece que deba apreciarse una diferencia jurídicamente significativa

31 Desde un principio, el Parlamento danés ha constituido una excepción digna de alabanza, y también a veces perturbadora.

32 Sección B.I.1.b) cc), Abs. Nr. 74-75.

33 BVerfGE 89, 155 (186).

34 Cfr. por lo demás Sabine GLE $\beta$, "Zum Prinzip der gegenseitigen Anerkennung", ZStW 116 (2004), pp. 353 y ss. (p. 361), que convincentemente explica cómo la protección jurídica del ciudadano justamente se refuerza mediante la armonización del Derecho penal; igualmente Isabelle JÉGOUZO, "Le mandat d'arrêt européen, acte de naissance de l'Europe judiciaire pénale", pp. 33 y ss. (p. 39) y Gonzalo QUINTERO OLIVARES, "Le mandat d'arrêt européen dans la perspective européenne d'unification de la justice pénale et la réglamentation espagnole", pp. 163 y ss. (pp. 164-172), ambos en Le mandat d'arrêt européen, cit. en n. 29. 
en el hecho de que tales infracciones se persigan únicamente mediante el reconocimiento recíproco y limitado de la acción penal de los demás Estados, es decir mediante recíproca asistencia jurídica establecida por la orden europea de detención, o bien a través de una «armonización general del Derecho penal de los Estados miembros ${ }^{35}$. Como ya se ha señalado, el elenco de delitos del art. 2.2 de la Decisión Marco ha sido ampliado ciertamente de modo casi "delictivo": un fallo monumental, también de los órganos constitucionales alemanes, que en ningún caso cabe imputar a la correspondiente atribución competencial sobre la que se funda la Decisión Marco ${ }^{36}$.

En conjunto, el apartado B.I.1.b) cc) de la sentencia del Tribunal Constitucional muestra con gran claridad hasta qué extremo pueden estar teñidos de subjetividad los juicios sobre la preservación de la estatalidad alemana. En muchos pasajes se siente uno transportado de nuevo al debate sobre la cuestión de si el creciente desplazamiento de tareas y competencias a la Federación habría socavado el principio federal mediante un procedimiento casi furtivo de lenta erosión. El proceso de integración europea se ha aproximado sin duda alguna a los elementos nucleares de la estatalidad. Pero también sigue siendo cierto que los órganos de la Unión Europea disponen solamente de competencias tasadas, y que el Parlamento Europeo no ha sido dotado hasta ahora de competencias normativas omnicomprensivas. De ahí que la Unión haya de actuar en el marco de un firme entramado jurídico, que delimita materialmente sus competencias. No dispone de una competencia sobre las competencias. No está en situación de ampliar unilateralmente el espacio jurídico que le ha sido atribuido. En fin, los Estados miembros siguen teniendo la última palabra, como se recoge de forma expresiva en el proyecto de Tratado constitucional europeo especialmente mediante el derecho de retirarse de la Unión, que pasa a ser formalmente reconocido (art. I-60). En tales circunstancias no cabe atribuir a la Unión Europea un carácter estatal, menos aún en contra de la voluntad declarada de todos sus miembros. Ahora bien, si la propia Unión sigue estando muy lejos de la estatalidad, tampoco parece posible que la República Federal haya podido padecer desestatalización alguna.

\section{III.4. PRINCIPIO DE PROPORCIONALIDAD}

Por lo que se refiere al principio de proporcionalidad, cabe asumir sin ambages la diferenciación que establece el Tribunal según los elementos relevantes del supuesto de hecho estén referidos al interior o al exterior del país ${ }^{37}$. En cualquier caso, la persecución penal en el extranjero representa un sacrificio

35 Así lo reconoce también Bernd SCHÜNEMANN, "Fortschritte und Fehltritte in der Strafrechtspflege der EU", Goldtdammer's Archiv 151 (2004), pp. 193, 197 s.

36 La consecuencia que detrae SCHÜNEMANN, op. cit., p. 207, de que la Decisión Marco, como "acto jurídico de ruptura", carecería de toda eficacia vinculante, no necesita ser impugnada en este lugar. El Tribunal Constitucional, en cualquier caso, no ha expresado duda alguna acerca de la validez de tal disposición.

37 Sección B.I.1.c) cc). Abs. Nr. 84-87. 
especial para un ciudadano alemán. Si él mismo se ha movido por el extranjero y ha cometido allí un delito, resulta por completo conforme a la lógica de las cosas - dicho en términos de Derecho internacional, conforme al principio de territorialidad dominante en Derecho penal- que el proceso tenga lugar precisamente donde residen las víctimas y donde más fácilmente cabe acceder tanto a los testigos como a los demás medios de prueba ${ }^{38}$. Distinto es que el delito en cuestión haya tenido lugar en el propio país. Apenas cabría objeción alguna a la valoración del Tribunal, para el que la persecución penal debería tener lugar fundamentalmente en el propio Estado. Aunque ciertamente sorprende que no se puedan encontrar en los fundamentos de la sentencia desarrollos específicos de esta diferenciación fundamental con referencia al caso concreto que había dado lugar al recurso de amparo. El hecho, tal y como se describe nada más comenzar la resolución, se refiere a "visitas a España del recurrente y a encuentros y conversaciones telefónicas con presuntos delincuentes "39; es decir, a acontecimientos que tuvieron lugar en España, por los cuales la Audiencia Nacional con sede en Madrid emite la orden europea de detención. De la exposición de las razones de la orden de arresto que emite el Tribunal Superior de Hamburgo (Hanseatisches Oberlandesgericht Hamburg) con fecha de 15 de octubre de 2004 resulta que el recurrente ha actuado "en España, Alemania y Gran Bretaña" supuestamente como "figura decisiva de la red terrorista Al-Qaida" ${ }^{40}$. Las explicaciones del Tribunal Constitucional no permiten inferir que los hechos tengan una relación dominante con Alemania. Para hechos complejos, con elementos referidos tanto al interior como al exterior del país, el Tribunal exige una ponderación concreta en el caso particular ${ }^{41}$; pero él mismo no actúa conforme a tal criterio, por más que precisamente en el recurso de amparo se trate en primer lugar de abordar un caso concreto sometido a juicio. De modo que también en tales pasajes se prueba que el Tribunal apenas se ha esforzado en proporcionar protección al derecho fundamental como garantía individual, y que más bien se ha servido del caso y de las supuestas lesiones del derecho fundamental para abordar un control abstracto y general de los parágrafos correspondientes de la Ley sobre asistencia jurídica internacional en materia penal.

Al controlar si la Ley alemana sobre la orden europea de detención respeta el principio constitucional de proporcionalidad, el Tribunal termina concluyendo que el legislador no ha hecho uso de los márgenes de actuación que le abría Decisión Marco para proteger a los ciudadanos alemanes. Para los hechos cuyos elementos estén referidos al interior del país es particularmente determinante el art. 4 , n. ${ }^{\circ} 7$ a) de la Decisión Marco, a cuyo tenor cabe denegar la ejecución de la orden de detención cuando el hecho se haya cometido en el territorio del Estado requerido; lo mismo ocurre cuando se ha iniciado contra la persona sospechosa un procedimiento penal en el propio Estado (art. 4, n. ${ }^{\circ}$

38 Cfr. al respecto Cornelius NESTLER, «Europäisches Strafprozessrecht”, ZStW116 (2004), pp. 336 y ss. (p. 338 s.).

39 Abs. Nr. 1.

40 Abs. Nr. 6.

41 Sección B.I.1.c) cc), Abs. Nr. 87. 
de la Decisión Marco) o cuando las autoridades judiciales del Estado requerido, en relación con la infracción que sea objeto de la orden de detención, hubieran decidido previamente sea no incoar acción penal, sea concluirla (art. 4, n. ${ }^{\circ} 3$ ). De la primera de ambas cláusulas (n. ${ }^{\circ}$ 7) no se hizo uso alguno en la Ley alemana de trasposición, las otras dos cláusulas (n. ${ }^{\text {os }} 2$ y 3 ) sólo se acogieron en medida limitada. En la correspondiente disposición del $₫ 9$ n. ${ }^{\circ} 1$ de la Ley sobre asistencia jurídica internacional en materia penal, que bajo la rúbrica "Jurisdicción concurrente" trata una serie de obstáculos a la entrega, no figura la apertura de diligencias penales por parte de la fiscalía del Estado, una actuación que genera expectativas en las que también confía el ciudadano implicado; y los n . $^{\text {os }}$ 1 y 2 del $₫ 83$ b de dicha Ley solamente se configuran como disposiciones facultativas. Son sobre todo estas dos deficiencias las que han movido al Tribunal Constitucional a dictar sentencia contra la Ley alemana sobre la orden europea de detención.

Con referencia al art. 4, n. ${ }^{\text {os }} 2$ y 3 de la Decisión Marco, cuesta cierto trabajo comprender que quepa en realidad plantearse el hecho de que no se hayan usado los márgenes de acción ofrecidos por el Derecho europeo. Conforme exige con claridad el Tribunal, los motivos allí mencionados deberían haber sido convertidos en impedimentos para la entrega de aplicación forzosa, sin que sea lícito que se mantengan como disposiciones facultativas ( $\$ 83 \mathrm{~b}$ IRG). Los fundamentos jurídicos de la sentencia no exponen ninguna especificación adicional al respecto ${ }^{42}$. Pero, como la proporcionalidad es un mandato constitucional que vincula a todas las autoridades y a todos los tribunales, parece que hubiera sido aquí más natural remitirse al respeto que deben a los principios del Estado de Derecho las instancias competentes para hacer uso de tales disposiciones facultativas, y limitarse a afirmar como principio constitucional que, por regla general, debería rechazarse la extradición ante la apertura de diligencias penales. En tal sentido, resultan más convincentes las explicaciones del Magistrado Gerhardt en su voto particular ${ }^{43}$ que la Sentencia adoptada por la mayoría de la Sala.

En relación con el hecho de que la Ley alemana no mencione la cláusula del art. 4, n. $^{\circ} 7$ a) de la Decisión Marco, la laguna en la protección jurídica ofrecida por la Ley sobre asistencia jurídica internacional en materia penal parece más grave a primera vista de lo que resulta en realidad. Porque en la mayoría de los delitos relacionados en el art. 2 de la Decisión Marco, si los hechos relevantes hubieran sido cometidos en Alemania, y atendiendo al principio de legalidad aquí vigente, parece casi inconcebible que por parte alemana no se hubiera también procedido al menos incoando diligencias preliminares; en otro caso habría que reprochar al fiscal competente una grave negligencia. En cuanto haya existido tal respuesta entra en juego al menos el $₫ 83 \mathrm{~b}, \mathrm{n}$. $^{\text {os }} 1,2$ de la Ley sobre asistencia jurídica internacional en materia penal. Incluso al recibir una orden de detención procedente de otro Estado miembro de la Unión Eu- 
ropea cabe aún incoar en Alemania diligencias preliminares ${ }^{44}$. El peligro de que un alemán vaya a ser entregado a otro país por un delito cometido en Alemania parece así sólo teórico; si acaso, se acabará comprobando que entrarán en consideración exclusivamente ciertos casos límite, para los que nunca cabrá poner como ejemplo el hecho que dio lugar al recurso de amparo, como ya se ha subrayado.

Finalmente hay que plantear la cuestión de si los motivos considerados decisivos por el Tribunal, especialmente no haber traspuesto el art. 4, n. $^{\circ} 7$ a) de la Decisión Marco en la Ley alemana, hacían verdaderamente necesario declarar la inconstitucionalidad, o si más bien no hubiera sido posible sanar el vicio por la vía de la interpretación conforme al Derecho europeo. Al igual que una Ley nacional adoptada para la trasposición de una directiva comunitaria debe ser interpretada a la luz de dicha directiva ${ }^{45}$, no debería caber duda alguna acerca de que el mismo proceder metodológico resulta exigido también en relación con las decisiones marco. El Tribunal de Justicia de las Comunidades lo ha establecido recientemente en el caso Pupino ${ }^{46}$, y su planteamiento concuerda plenamente con el principio de interpretación conforme al Derecho internacional que el propio Tribunal Constitucional alemán ha desarrollado. En su voto particular, el Magistrado Gerhardt se apoya especialmente en tal argumento ${ }^{47}$, consolidado por el Tribunal de Justicia poco antes de ser emitida la sentencia del Tribunal Constitucional, y que sorprendentemente no recibe atención alguna en la decisión de la mayoría. La declaración de inconstitucionalidad de la ley en su totalidad sólo resulta en cierto modo plausible adoptando el punto de partida del Tribunal Constitucional. Éste cree haber descubierto una laguna de protección jurídica que amenaza la libertad individual de los ciudadanos, y pretende, en una cuestión fundamental como ésta, una claridad absoluta en la ley, que no podría ser lograda recurriendo al acto jurídico de la Unión Europea como criterio de interpretación y a la aplicación del principio constitucional de proporcionalidad. La cadena de argumentos del Tribunal Constitucional resulta comprensible, pero no llega a resultar convincente; porque, justo en los delitos cometidos en Alemania que en virtud de una orden europea de detención pudieran dar lugar a la extradición, estamos más ante una serie de imaginarios casos hipotéticos que ante supuestos que puedan darse en la realidad. De ahí que hubiera sido más adecuado que el Tribunal Constitucional se hubiera planteado no la nulidad de toda la Ley que ha traspuesto la Decisión Marco,

44 Cfr. AHLBRECHT, cit. en n. 6, p. 46, que incluso sostiene que en tales circunstancias "habría que exigir expresamente" la incoación de un procedimiento penal en Alemania; SEITZ, cit. en n. 6 , p. 549 .

45 EuGH, Rs. C-106/89, Rec. 1990, I-4135, número marginal 8 (caso Marleasing); Rs. C334/92, Rec. 1993, I-6991, número marginal 20 (caso Wagner Miret); Rs. C-91/92, Rec. 1994, I-3325, número marginal 26 (caso Faccini Dori); véase también Paul CRAIG / Gráinne DE BÚRCA, EU Law, Oxford 2003, pp. 211 y ss.

46 Sentencia de 16 de junio de 2005, RS. C-105/03, Rec. 2005, I-5285, número marginal 43.

47 Sección I.1, Abs. Nr. 188. 
sino más bien, como propone el Magistrado Gerhardt ${ }^{48}$, negar su aplicabilidad en determinados supuestos. Hay que tener en cuenta también los daños causados por la sentencia. De la prensa se deduce que han quedado paralizadas todas las extradiciones entre Alemania y España ${ }^{49}$. Teniendo en cuenta la disolución del Bundestag y las nuevas elecciones, habrá que esperar además un cierto tiempo hasta que las necesarias medidas reparadoras sean puestas en marcha.

\section{VICIOS DE LA LEY ALEMANA SOBRE LA ORDEN EUROPEA DE DETENCIÓN REFERIDOS AL PROCEDIMIENTO DE TUTELA JUDICIAL}

El Tribunal Constitución ha constatado aún un segundo vicio de inconstitucionalidad referido al procedimiento de tutela judicial. A su juicio, la decisión que aprueba la entrega debería ser judicialmente recurrible, en contra de lo dispuesto por el $\$ 74$ b de la Ley de asistencia jurídica internacional en materia penal, por discurrir en el ámbito del derecho fundamental del art. 16.2 GG y no tener como objeto solamente consideraciones políticas al margen de los derechos subjetivos judicialmente exigibles ${ }^{50}$. Esta interpretación es argumentada de modo concluyente, sin apenas acoger márgenes de duda; pero en última instancia, como se expone a continuación, sus bases son inseguras. Es evidente que el legislador no ha caído en la cuenta de que, al fijarse criterios objetivos y precisos para el eventual rechazo de una extradición $(\$ 83$ b de la Ley de asistencia jurídica internacional en materia penal), se han modificado sustancialmente las coordenadas del sistema. La situación jurídica se complica aún más por el hecho de que incluso la extradición de un extranjero (y no sólo la de uno de los "extranjeros arraigados en el interior" en el sentido del $₫ 80$ II IRG) tiene aspectos que afectan a los derechos fundamentales. Toda detención, como limitación de la libertad, supone una intervención en el derecho fundamental del art. 2.2 GG; en cualquier caso, también sería decisivo el art. 2.1 GG. No puede tratarse, pues, sólo de establecer nuevas reglas para las personas de nacionalidad alemana; más bien, según el punto de vista expresado por el Tribunal Constitucional, todo el sistema está necesitado de revisión. Sin embargo, si en un futuro procedimiento de extradición han de producirse dos decisiones, una primera sobre la admisibilidad de la extradición y otra subsiguiente para su aprobación, ambas susceptibles de recurso ante los tribunales, podrían surgir situaciones procesales de especial complejidad. Precisamente a partir de la exposición del Tribunal Constitucional se hace evidente que se producirán múltiples interferencias desde el punto de vista del objeto del litigio, puesto que en

48 Sección II, Abs. Nr. 200.

49 Die Welt, 23.7.2005.

50 Sección B.I.2, Abs. Nr. 101-115. 
cada caso habrá que tener en cuenta la posición jurídica del afectado. Incluso una sumaria comparación entre el $₫ 83$ IRG por un lado y del $₫ 83$ b IRG por el otro muestra la extrema cercanía objetiva entre la decisión sobre la admisibilidad de la extradición y la decisión sobre su aprobación.

Tales consecuencias prueban suficientemente que fue un error la decisión de preservar el doble procedimiento en el sistema derivado de la orden europea de detención. Se impone la impresión de que la Ley alemana de trasposición de Decisión Marco debe ser revisada mucho más profundamente aún de lo que exige el Tribunal Constitucional. Sobre todo, procesos judiciales paralelos cuyos objetos se solapan no pueden constituir la solución ideal. El procedimiento de la orden europea de detención está por principio abocado a concentrar en una única instancia la decisión sobre la entrega solicitada, en concreto en una autoridad judicial (cfr. especialmente los arts. 6.2 y 15 de la Decisión Marco). Parece recomendable someter a un control judicial todas las verificaciones que guarden relación con los derechos fundamentales de los afectados, reduciendo la aprobación de la entrega, como acto jurídico posterior, exclusivamente a apreciar cuestiones generales de oportunidad política (en la medida en que tales cuestiones aún subsistan en un ámbito orientado por los derechos fundamentales, y si es que la Decisión Marco tolera una doble actividad de tal género). Entretanto subsistirá una enorme confusión.

Hay fundamento para pensar que en Alemania se ha incurrido en un error de principio en relación con el concepto de "Justizbehörde" (autoridad de la Justicia) contenido en la Decisión Marco. Como muestra precisamente la tramitación del proceso ante el Tribunal Constitucional, con sus antecedentes en Hamburgo, se parte entre nosotros de concebir al Ministerio de Justicia como "Justizbehörde" (autoridad de la Justicia) en el sentido de la Decisión Marco sobre la orden europea de detención. En las alegaciones del Gobierno se dice simplemente que, conforme al art. 6 de la Decisión Marco, se defiere a los Estados Miembros la determinación de la autoridad nacional competente ${ }^{51}$. Tal afirmación es correcta, pero al mismo tiempo resulta también equívoca, en la medida en que con su confusa referencia a la competencia de la Federación conforme al art. $32.1 \mathrm{GG}$ pretende preservar las competencias del Gobierno federal ${ }^{52}$. El texto inglés habla claramente de una "judicial authority", es decir, de una instancia del poder judicial; también el texto francés deja ver con claridad, mediante la expresión "autorité judiciaire", que precisamente no se trata del poder ejecutivo ${ }^{53}$. Este resultado ofrecido por una interpretación conforme al puro sentido literal de la expresión se ve confirmado por la finalidad de la entrega conforme a la orden europea de detención. Debe ser excluida toda discrecionalidad política, las decisiones que sean necesarias deben quedar ex-

51 BT-Drucksache 15/1718, cit. en n. 3, p. 10.

52 En Austria no se ha asumido tal interpretación del texto, cfr. SAUTNER, cit. en n. 6, pp. 332,339

53 El texto español habla de "autoridad judicial" y el holandés utiliza el concepto de "rechterlijke autoriteit. 
clusivamente en manos de los jueces ${ }^{54}$. En tal sentido, la ley alemana de trasposición de la Decisión Marco requiere una revisión que afecte a sus mismos principios $^{55}$, sin conformarse con atender a los requerimientos del Tribunal Constitucional $^{56}$. La actual regulación alemana descansa aún sobre la ilusión de que la decisión sobre la admisibilidad de la entrega adoptada por el Tribunal Superior del Land constituye simplemente el paso previo para una entrega que, finalmente, requiere la aprobación del ejecutivo. También el Tribunal Constitucional parte en su sentencia de esa misma concepción, que sin embargo no está en armonía con la regulación contenida en la Decisión Marco.

\section{OBSERVACIONES FINALES}

En el futuro, los problemas con la orden europea de detención procederán seguramente no tanto de las razones que ha planteado el Tribunal Constitucional como del recelo ante insuficiencias en la garantía de los principios del Estado de Derecho por parte de alguno de los Estados miembros de la Unión y del peligro de una persecución política encubierta. Por más que se hayan previsto suficientes disposiciones jurídicas de protección contra tales riesgos (art. 6 del Tratado de la Unión en conexión con el art. 1.3 de la Decisión Marco, y $\$ \$ 6.2$ y 73 de la Ley de asistencia jurídica internacional en materia penal) ${ }^{57}$, nunca será fácil para los jueces desestimar tales suposiciones y el consiguiente rechazo de una solicitud de entrega presentada mediante una orden europea de detención. Urge también una revisión del catálogo de delitos del art. 2.2 de la Decisión Marco para separar el grano de la paja. Por lo demás, sigue resultando incomprensible la razón por la que realmente se han tomado distancias respecto de la garantía jurídica de la doble penalización por el mismo delito ${ }^{58}$. En el fondo, tal innovación significa una expresión de desconfianza recíproca. Se asume implícitamente que alguno de los Estados miembros de la Unión no muestra el celo requerido en la lucha contra ciertas manifestaciones de acciones sociales indeseables, por lo que será preciso "meterlo en cintura". Se otorga preferencia por tanto al interés en la

54 Por esta misma razón son criticadas ciertas modalidades de la ley francesa de trasposición por parte MAURO, cit. en n. 29, pp. 216 y s.

55 Irreflexiva resulta por ello la afirmación que figura en la exposición de motivos del Gobierno Federal, BT-Drucksache 15/1718, cit. en n. 3, p. 11, según la cual el sistema existente en Alemania no necesitaría "reforma sistemática alguna".

56 AHLBRECHT, cit. en n. 6, p. 42, informa de hecho de que el mantenimiento del doble procedimiento ha provocado enorme desazón en la Unión Europea y en algunos Estados miembros. También anticipa sus dudas SEITZ, cit. en n. 6, p. 547. Michel MASSÉ, cit. en n. 29, pp. 47 y ss., 54 , dice inequívocamente que la orden de arresto europea conduce a "colocar fuera del circuito a las embajadas y a los gobiernos", el procedimiento sería ahora "exclusivamente judicial". El problema no es apreciado por Jörg SCHWALM, "Le mandat d'arrêt européen en Allemagne", en Le mandat d'arrêt européen, cit. en n. 29, pp. 101 y ss. (p. 108).

57 Cfr. al respecto VENNEMANN, cit. en n. 3, pp. 114-120.

58 Intenta aclararlo la exposición de motivos del Gobierno Federal, BT-Drucksache 15/1718, cit. en n. 3, p. 17. 
persecución y la penalización, mientras que se atribuye menor importancia a la decisión consciente de un Estado a favor de la no penalización. Precisamente en una comunidad de valores, sin embargo, sería natural suponer que la decisión de no penalizar una conducta no se apoya por ejemplo en desvaríos ideológicos o en el intento de singularizarse, sino que podrá invocar razones de peso. Por ello cabe perfectamente considerar desafortunada en este extremo la Decisión Marco sobre la orden europea de detención.

Tras la lectura de los fundamentos jurídicos de la sentencia, el lector tiene la impresión de que el caso no era precisamente idóneo para una sentencia de grandes vuelos, por más que el Tribunal Constitucional tuviera la intención de poner de manifiesto, una vez más, su concepción acerca de los límites de la integración europea. El preludio resultó dramático, con la adopción de una medida cautelar conforme al $₫ 32$ de la Ley reguladora del BVerfG ${ }^{59}$. En su momento, el Tribunal Constitucional acertó al adoptar esta medida, dado que, a la vista de las quejas expuestas, no cabía excluir que el recurrente pudiera sufrir perjuicios de imposible reparación ulterior. Pero el posterior curso del proceso poco lugar ha dado para cuestiones verdaderamente agudas. De ahí que hubiera tenido mucho mayor sentido emitir una sentencia más orientada hacia el caso concreto, en lugar de declarar con redoble de tambores la nulidad de toda la Ley alemana sobre la orden europea de detención. De todos modos, el legislador ha recibido la lección de que, en la trasposición del Derecho de la Unión y de la Comunidad, no puede concebir su tarea como la ejecución encomendada a autómata servil; sino que, dentro de ciertos límites, que deben ser determinados en cada caso, le corresponde también asumir sus propias responsabilidades.

ABSTRACT. By a spectacular judgment of 18 July 2005, the German Federal Constitutional Court declared the German statute implementing the Framework Decision on the European arrest warrant unconstitutional. It found that the statute did not sufficiently ensure the right of a German citizen not to be surrendered in case the relevant offence had been committed in Germany. Little importance is attached by the Court to Art. 23 of the Basic Law, which proclaims the readiness of Germany to contribute to the establishment of the European Union. Cooperation in matters of criminal law is encompassed by that pledge, a fact which the Court overlooks or underrates. The Court also errs in requesting a review of governmental decisions to grant surrender. According to the Framework Decision, which on its parts invites serious criticism on account of its list of offences where the principle of double criminality is excluded, surrender to another member State of the European Union is to be handled exclusively by a judicial body, no room being left for discretionary political decisions. On the whole, to strike down the statute in its entirety would appear to be a judicial response not justified in the circumstances of the case.

59 BVerfG, 2 BvR 2236/04 de 24.11.2004. 